some months, but was accustomed previously to drink two or three pints of beer in the day. There was no history of syphilis, except that before enlistment he had what appears to have been a non-infecting chancre with suppurating bubo, from which there remains a scar in the left groin.

He stated that about the end of July last he strained his left leg, and that in a few days afterwards he found a small swelling in the ham, which gradually grew larger, and that after a while he noticed pulsation in it. Previous to admission he felt pain and numbness down the leg and in the foot when walking or standing, but none while lying. The tumour was in the centre of the left popliteal space, and measured three inches in the transverse diameter by two in the perpendicular. The circumference round the patella was half an inch more than that of the corresponding limb. The tumour was very expansile, with a full pulsation, which could be controlled by digital compression of the femoral below Poupart's ligament. The patient also had large varicose veins on the same leg. He was immediately ordered to bed on admission, and got beef-tea diet, with eight ounces of fish added, and was told to drink but little fluid. He was directed to practise digital compression of the femoral artery himself from time to time.

On the forenoon of the 6th October, Dr. Macdougal, of Carlisle, kindly brought an Esmarch's bandage and band and a Signorini's tourniquet. At first the bandage was applied to the limb, and then the band to the lower third of the thigh, the bandage being removed. The effect was to stop the pulsation in the tumour very nearly completely, but the pain produced was too severe to be borne. The band was then removed and the bandage applied as before, tightly from the toes up to the knee, then loosely and tight again above the knee, and pinned on ; Signorini's instrument was at the same time applied below the groin. (Time 12.10 P.M.) The pulsation in the tumour was thus almost completely stopped, and at first but little pain was produced. After a short time, however, the tourniquet began to cause pain, which the patient tried to bear until he suddenly fainted. The tourniguet was then removed and brandy administered, Esmarch's bandage being left on. During the syncope the pulsation in the tumour ceased, but quickly returned with the reaction after the stimulant. The tourniquet was then replaced, but not so tightly, and when the bandage had been on for one hour it was removed. Soon afterwards, a "Carte's compressor" was applied below the "Signorini," pressure being kept up with the two instruments, each being constantly shifted; but the pulsation in the tumour was only incompletely controlled. At 4.30 P.M. no appreciable change had taken place, but the patient was learning to manage the instruments himself and to lend valuable assistance. At 6.30 P.M. the pulsation in the tumour appeared to be more easily controlled. At 9.30 the improvement was not maintained. Incomplete compression was continued, but for a few hours during the night the instruments were removed to permit of some sleep being obtained. While the instruments were off, pain was felt in the tumour, and the patient was glad to have the compression reapplied.

On the 7th, at 11 A.M., I injected half a grain of morphia under the skin of the thigh of the affected limb. The effect was most beneficial. From that time complete compression was kept up, causing scarcely any pain. At 2.30 P.M. the compression was momentarily eased for observation, and the pulsation in the tumour was found to be very feeble. At 4.30 P.M. I found the pulsation to be completely controlled with very little pressure on the femoral, and I concluded that the clot was formed at that time. The compression was maintained. At 6.30 P.M. I loosened the instrument for observation, and found the tumour to be quite free from pulsation.

On the 8 th, at 10 A.M., the tumour was being consolidated. There was good collateral circulation. The foot was warm, and a superficial artery at the inside of the knee-joint was felt pulsating with almost the volume of a radial.

Slight compression was kept on the femoral for two days more, and on the 19th he was discharged quite cured, only a little stiffness remaining in the leg.

I have to thank Dr. Macdongal for the kind assistance he gave me and for the interest he took in the case. Carlisle.

\section{SOME DYNAMOMETRICAL OBSERVATIONS ON MIDWIFERY FORCEPS AND THE FLEXORS OF THE HAND.}

BY G. F. MASTERMAN, L.K.Q.C.P., M.R.C.S.L., IATE ASSISTANT-SURGEON AND LECTURER ON MATERIA MEDICA, GENERAL MILITARY HOSPITAL, ASUNCION.

IN Dr. Barnes's paper, published in THE LANCET of May 17th, on the Use of the Forceps, the long and short forms of that instrument are compared and contrasted, and it is especially pointed out that the former not only possess the greater power in traction and leverage, but that they alone are able to compress the foetal head. The short forceps, it is there stated, as it is with equal emphasis and at greater length in Dr. Barnes's "Obstetrical Operations," has absolutely no effective compressive power, and that it clings to the head only from the curve of its fenestrated blade aided by the pressure of the vaginal walls.

Now, with the greatest respect for the opinions of so distinguished a teacher, I submit that the above statement should be considerably modified ; for, the forceps being an example of a lever of the first order, the power being applied at the handles, the edge of the lock being the fulcrum and the blade the other arm of the lever, it follows, cceteris paribus, that the shorter the blades in proportion to the length of the handles the greater is the potential force expended on the object within their grasp.

And I would here suggest that the perror of regarding the long forceps as necessarily the more powerful instrument has arisen partly from its more formidable, or, as Tyler Smith calls it, "martial" look, but mainly because one sees short foreeps with handles so extremely small and blades so thin that all power, save that of feeble traction, appears to be sacrificed to innocence in appearance and facility of introduction. But it is evident that these defects are accidentals, and do not belong more to one form than the other; for, if we compare the short forceps of Smellie or Collins with the long one of Lever or Ashwell, we shall at once see, bearing the properties of the lever in mind, that the former are by far the more powerful instruments, provided, of course, that the maker has given each of them blades aud shanks of equal strength. And, on the other hand, if we compare Barnes's long with Simpson's short forceps, we are contrasting an instrument powerful in all respects with one of the weakest; but nevertheless most useful just at the end of a tedious natural labour.

Not being able to find in any English work a table similar to that drawn up in 1865 by Delore for French instruments -but which I have not seen,--giving the comparative size and power of the forceps generally used in this country, and thinking that it might be interesting to the profession, after the late discussion at the Obstetrical Society, to have such data, I have made a few careful measurements and experiments, with the following results :-

Long Forceps.

\begin{tabular}{|c|c|c|c|c|c|c|c|c|}
\hline & & & & $\begin{array}{l}\text { Length } \\
\text { of } \\
\text { handle } \\
\text { in } \\
\text { inches. }\end{array}$ & $\begin{array}{c}\text { Length } \\
\text { of } \\
\text { (shank } \\
\text { and) } \\
\text { blade. }\end{array}$ & $\begin{array}{l}\text { Total } \\
\text { length. }\end{array}$ & $\begin{array}{l}\text { Ratio of } \\
\text { handle } \\
(=1) \text { to } \\
\text { blade. }\end{array}$ & $\begin{array}{l}\text { Result } \\
\text { ant of } \\
50 \text { lb. } \\
\text { pres- } \\
\text { sure, in } \\
\text { lbs. }\end{array}$ \\
\hline Ashwell's & & & & $3 \frac{1}{4}$ & $10 \frac{3}{4}$ & 14 & $3 \cdot 3$ & $10 \cdot 5$ \\
\hline Barnes's & & $\ldots$ & $\ldots$ & $4 \frac{1}{2}$ & 10 & $14 \frac{1}{2}$ & $2 \cdot 2$ & $15 \cdot 4$ \\
\hline Blundell's & & $\ldots$ & & $4 \frac{1}{2}$ & $9_{\frac{1}{2}}$ & 14 & $2 \cdot \overline{1}$ & $19 \cdot 0$ \\
\hline Hodge's & $\ldots$ & $\ldots$ & $\ldots$ & 8 & 9 & 17 & $1 \cdot 1$ & $61 \cdot 0$ \\
\hline Lever's ... & $\ldots$ & $\ldots$ & $\ldots$ & $4 \frac{1}{4}$ & $10 \frac{1}{4}$ & $14 \frac{1}{2}$ & $2 \cdot 4$ & $13 \cdot 4$ \\
\hline Simpson's & $\ldots$ & $\ldots$ & & $4 \frac{3}{4}$ & $8 \frac{3}{4}$ & $13 \frac{1}{2}$ & $1 \cdot 8$ & $20 \cdot 2$ \\
\hline
\end{tabular}

Short Forceps.

\begin{tabular}{llll|l|l|r|r|r} 
Clarke's & $\ldots$ & $\ldots$ & $\ldots$ & $4 \frac{1}{4}$ & 7 & $11 \frac{1}{4}$ & $1 \cdot 6$ & $31 \cdot 0$ \\
Collins's & $\ldots$ & $\ldots$ & $\ldots$ & 4 & 6 & 10 & $1 \cdot 5$ & $34 \cdot 0$ \\
Denman's & $\ldots$ & $\ldots$ & $\ldots$ & $4 \frac{1}{4}$ & $6 \frac{1}{2}$ & $10 \frac{3}{4}$ & $1 \cdot 5$ & $33 \cdot 5$ \\
Inglis's ... & $\ldots$ & $\ldots$ & $\ldots$ & $2 \frac{1}{2}$ & 8 & $10 \frac{1}{2}$ & $4 \cdot 2$ & $10 \cdot 0$ \\
Simpson's & $\ldots$ & $\ldots$ & $\ldots$ & 2 & $7 \frac{1}{3}$ & $9 \frac{1}{2}$ & $3 \cdot 7$ & $9 \cdot 6$ \\
Smellie's & $\ldots$ & $\ldots$ & $\ldots$ & $4 \frac{1}{4}$ & 6 & $10 \frac{1}{4}$ & $1 \cdot 4$ & $36 \cdot 0$
\end{tabular}

Lever of the third orcher (intermediate length).

\begin{tabular}{lllllllll|l|l|l} 
Assalini's & $\ldots$ & $\ldots$ & $\ldots$ & | & $5 \frac{1}{4}$ & $\mid$ & 7 & 121 & 1.02 & $25 \%$
\end{tabular} 
The table explains itself, with the exception of the figures in the last column. These give the pressure which a weight, or any other compressing force, equal to $50 \mathrm{lb}$. avoirdupois, acting on the middle of the handle (or, in the case of Hodge's, two inches from its distal extremity), would produce in the centre of the are of the head curve. And I should explain that the position of the latter point varies greatily, even in instruments of the same length, from the presence or absence of a shank, and, to a slight extent, from the varying radius of the pelvic curve in those possessing it. The force was determined indirectly by means of sliding weights hung on a long balance-beam, graduated into inches and tenths, side by side with the blade under observation.

Although only one blade was taken for the experiment, it is assumed that the pressure would be given by means of both, the hand or hands grasping both handles with the head of the foetus between the fenestrx. And, also, it is clear that although, for the sake of simplicity, the resulting pressure is calculated as acting on two points only in the line of the minor diameter of the oval, in actual practice it would be diffused over the whole surface within the grasp of the blades; and, as this differs very greatly, the actual compressive power would vary to the same extent.

Now it will be seen from the table that the most powerful instrument is that of Hodge, which is designed on the continental model with French locks; but the handles are so long and gape so widely that it could scarcely be used, I think, except in the continental (lithotomy) position. The next in power is Smellie's short forceps ; then three more of the same class, before we come to Simpson's in the long division, - and so on ; in fact, if we exclude Hodge's, as an exceptional form, it is clear that the short forceps are collectively the more powerful instruments; but I leave the figures to speak for themselves. I should mention, however, the loss of power due to flexure of the blades, and especially of the shanks. This is, of course, the greatest in the long forceps, with the exception of those of Barnes and Simpson, which are very strongly made. One blade of Lever's, with the handle firmly fixed in a vice, yielded from 51 in. to 66 in. as a suspended weight of $20 \mathrm{lb}$. was slowly moved from the centre to the point. Assalini's gave, under the same test, from $78 \mathrm{in}$. to $82 \mathrm{in}$; whilst the short forceps of Simpson, with their stout blades pierced only by a narrow fenestra, bent only from $20 \mathrm{in}$. to $38 \mathrm{in}$. This loss may be compensated for, as Dr. Thorburn pointed out, ${ }^{1}$ by separating the handles close to the lock by a screw passing through one of them, or by the introduction there of a wedge.

As the force employed must (even when supplemented by a screw) be ultimately referred to the hand of the operator, it occurred to me that we might approximately estimate the value of this force by fixing one of the handles of the forceps and converting the blade of the other into a steelyard. I have had an instrument of the kind made; the handles, of iron guarded with wood, are four inches long, and exactly resemble those of Collins's forceps; the bar is twenty-four inches long and one inch broad, strong enough to be sensibly inflexible when fully loaded, and carefully graduated; the sliding weight gives an inertia of from $20 \mathrm{lb}$. to $240 \mathrm{lb}$, and is so supported on the inclined base that when at rest the ends of the handles are always one inch apart. As the mean power of the hand would be exerted in the middle of the handles, it is assumed that the total force is acting there.

I have had time to make only a few trials of hand-strength with the instrument, but I am surprised at the results. We are all familiar with the perfect mobility, the firmness and precision, and yet fairy-like delicacy of touch displayed by educated fingers, but I had so underrated the power they possess that my first sliding weight gave but $100 \mathrm{lb}$. as its maximum. I have had to move more than double that weight.

In order to avoid bringing the leverage of the forearm involuntarily into action the experimenter either sits with the handles level with his elbow, or, if standing, as one generally does when using the forceps, keeps the arm firmly tixed against his side; then, grasping the handles somewhat obliquely with the whole of the palm within their length, contracts the fingers and thumb as strongly as he can; the weight is then moved smoothly from the centre until it overpowers his strength. The weight that can be merely lifted is, of course, far greater than that which can be sustained. As examples of the former case, I found that a young lady - a good lawn-tennis player-could lift $70 \mathrm{lb}$, a confrire $122 \mathrm{lb}$., a stalwart blacksmith $225 \mathrm{lb}$. My own hand, with the handles level with the elbow, raised $95 \mathrm{lb}$; but, standing with the arm rigidly fixed to the side, $110 \mathrm{lb}$; with the leverage of the arm, $150 \mathrm{lb}$. But I could not sustain either for more than thirty seconds, and not more than $50 \mathrm{lb}$. for five minutes. My impression is, that in using the forceps in actual practice, I rarely exert, except when I am using both hands, a pressure exceeding $50 \mathrm{lb}$. on the handles. Now, with Simpson's forceps, this would give $20 \mathrm{lb}$. distributed over about one-fourth of the head-a force that is scarcely appreciable beside the enormous pressure of a contracting healthy uterus, and which must surely do but little in compressing or moulding the globe within the grasp of its blades; and we must remember that, when these have seized the head, still wholly within the uterus, quite one. third of that organ is encircling them and it, and exerting a compressing power which it is scarcely an exaggeration to say should be estimated in centals rather than pounds; its contraction, moreover, being probably rendered more intense by the irritation of the foreign body within it.

How, then, can we judge, except in the case of abso. lute uterine inertia, how much of any apparent moulding of the head may be due to the forceps, and how much to the uterus itself? And, again, in pulling a grasped elastic spheroid through a ring smaller than itself-to use the old illustration,--is there really any need for a compressive power in the tractor at all? Will not the inverted wedge-action of the ring itself produce the necessary elongation and diminu. tion in diameter? All that is essential is that the tractor shall have such a shape that it cannot slip off, that it shall be smaller than the ring, and that there shall be sufficient vis a fronte to overcome the passive resistance of the spheroid. And in using the long forceps I have been struck with the facility with which a head that had made no advance after hours of severe pains was brought down, but it did not seem to me that it was due to any compressive power in the comparatively weak instrument (Lever's) I generally use, but rather to the circumstances that the head was steadied, that it was placed in a more favourable position, and that the lines of traction, of exit and uterine force were coincident. For, when the head is above the brim, traction is made almost in the axis of the patient's body and of the uterus, and the latter, containing nearly the whole of the fotus, is acting with its greatest mechanical advantage, contracting, but uncontracted, like a spring which is beginning to uncoil.

But when short forceps are being used, and the head is within the cavity of the pelvis or pressed against the perineum, the conditions are very different : traction has to be made downwards, forwards, and then upwards, in the line of Carus's curve ; the uterus, greatly contracted, is acting with shortened fibrille, like a spring half uncoiled; and the body it is extruding is lying most disadvantageously for its passage, the uterine force, acting in a right line, tending to force the head on to the coccyx and through the perineum instead of through the osteum vaginæ. This will be more clearly seen if we imagine the sharp curve formed by the coccyx and the lower part of the sacrum to be reduced to a wedge with right-angled sides; then, the uterine force acting perpendicularly to its base, it would evidently lose half its momentum by impinging on the inclined plane. I con tend, therefore, that an instrument which extracts a tightly impacted head under these circumstances does more itself, if I may use the expression, and is much less helped by the natural expulsive forces, than one which has seized it above the brim; and that, without reference to the table I have given, it is evident that short forceps, with handles, say, four inches in length, must be more powerful compressors as they are than they would be if a shank were inserted between their locks and their blades, or the latter doubled in length.

At the bottom of the table I have placed Assalini's ad. mirable instrument, which differs from the others in being a lever of the third order. It is little used in this country, and Dr. Braxton Hicks made the same objections that Dr. Barnes does, ${ }^{2}$ when I was telling the former how useful I found it-that it has little holding and no compressing power, and is very liable to slip. Now, except when the head is very high up, the hand (or hands) grasps the flattened shanks exactly between the fulcrum and the centre of the blade; the force employed is, therefore, equally divided 
between them; so, taking the estimate of my own strength as an example, a pressure of $25 \mathrm{lb}$. could be kept up for a long time, and for a shorter period-especially with both hands - three times as much if it were necessary. The flexure of the shanks is a positive advantage, for, as it is impossible to make them meet, there is little loss of power, and the curvature of the blades being lessened in front greatly assists in giving that ellipsoidal form to the head which most facilitates its exit, whilst it is never so great as to endanger their hold; I have never known them to slip, and they can be introduced and locked, it seems to me, more readily than any other form.

I may add, in conclusion, that I use the forceps freely, in mercy to the mother and consideration for the safety of the child: the short forceps about once in every eight labours, including those simple cases in which $I$ have, unconsciously to the patient, slipped in Simpson's little instrument to help a delayed hear through the ostium vagine, and so spared her perhaps an hour's pain ; the long forceps four times in the last five years, but never through an undilated os. Craniotomy I have performed but once in my life, and then on a dead child; and, I am thankful to say, I have never had the misfortune to inflict the slightest injury on the mother, and only temporary mischief on the child, however great the force I have been obliged to employ.

Ixworth, Suffolk.

\section{9 attirutor}

\section{HOSPITAL PRACTICE, BRITISH AND FOREIGN.}

Nulla autem est alia pro certo noscendi via, nisi quamplurimas et morborum et dissectionum historias, tum aliorum, tum proprias collectas habere, et inter se comparare.-MoreAG M De Sed. et Caus. Morb., lib. iv. Procemium.

\section{CHARING-CROSS HOSPITAL.}

EPITHELIOMA OF BACK OF HAND; REMOVAL.

(Under the care of Mr. BELLAMY.)

FOR the notes of this somewhat rare case we are indebted to Mr. Albert Leahy, surgical registrar.

William L-, aged sixty-one, a powerful-looking labourer, was admitted June 3rd, 1879. About eighteen months ago he first noticed a small swelling in the centre of the dorsal surface of his right hand; this increased slowly, and in six months reached the size of a cherrystone, and had the appearance of a large wart. Taking the advice of a friend, he tried the application of "spirits of salt." The growth became rather painful and inflamed, and eventually fell off, leaving a raw granulating(?) surface. The hand and fingers were odematous. The ulcer increased and became more painful, accompanied by great pain in the arm.

On admission, there was a granulating surface about the size of a florin, with small readily-bleeding granulations. The surface of the ulcer was slightly raised above the level of the true skin, and its edges were rather prominent. There was infiltration and thickening of the tissues in the immediate vicinity of the ulcer, and it discharged freely. It was considered epitheliomatous from the first, and after a careful examination by Dr. Sangster it was considered advisable to remove it. This was accordingly done on July 10th by a free incision, giving the surface a wide margin and going down to the bone. 'The periosteum was rather rough, and gave the appearance of being involved.

The wound was dressed with carbolic oil and subsequently with iodoform; it looked healthy but suspicious, and will probably soon require more energetic treatment.

Microscopical examination showed the removed mass to be true epithelioma.

\section{WEST NORFOLK AND LYNN HOSPITAL.}

TWO CASES OE TUBERCULAR LARYNGITIS, ONE FATAL, THE OTHER RELIEVED BY TRACHEOTOMY.

(Under the care of Dr. DALE.)

FOR the notes of the following cases we are indebted to Mr. Arthur G. Blomfield, M.R.C.S., house-surgeon.
CASE 1.-J. C- aged thirty-eight years, labourer, was admitted on December 26th, 1878, complaining of loss of voice and failing health. There was a history of strong phthisical tendency in the family: one brother died of phthisis; a sister was at this time under treatment for loss of voice, \&c. (see Case 2); and another sister had lately shown symptoms of laryngeal disease.

The patient had always enjoyed good health until five or six months' before, when he first noticed that his voice was hoarse and getting weak. This hoarseness gradually increased; he had a slight cough about this time, and had expectorated a good deal of mucus, at times blood-tinged. He has also lost flesh rapidly.

On admission he looked much emaciated, and was very weak; the voice was reduced to a whisper; cough not well-marked; expectoration muco-purulent. Examination of the larynx externally showed thickening, and a degree of increased hardness to the touch, which, however, gave rise to very little pain. Examination by the laryngoscope was attended with difficulty, and but little was made out; the left cord was, however, seen to be thickened and prominent. There was dulness on percussion under the right clavicle in front with slight crepitation, but no marked dulness was detected in other parts of the chest.

The patient was placed on meat diet. He was ordered to take four grains of iodide of potassium thrice daily, and to inhale by means of Siegle's steam-spray inhaler a twograin solution of nitrite of silver three times a day. Under this treatment he continued without any marked change until Jan. 4th, when four grains of hypophosphate of soda was substituted for the iodide of potassium.

On Jan. 6th there was a marked change. The patient had considerable dyspnoea, with inability to expectorate freely; thick tenacious mucus hung abont the fauces, and required to be removed with the hand. Edema glottidis was suspected, but did not exist. Later on in the day he appeared better, the breathing being easier, and he took milk and beef-tea freely, but he died suddenly in the night while asleep, and apparently from exhaustion.

Necropsy, thirty-six hours after death.-The larynx and upper part of trachea were carefully dissected out. On opening the larynx from behind, the mucous membrane was found to be much congested and thickened, the surface being also studded with small tubercles which in parts had ulcerated, leaving small superficial erosions. The mucous membrane of trachea was congested and thickened. The right vocal cord was entirely destroyed by ulceration, and the cicatrix was adherent to the lower part of ventricle, forming together a large depression as contrasted with the left vocal cord, which was much thickened and prominent. Both lungs were studded throughout with small miliary granulations; the apices and bases being especially so. The heart was normal. On cutting into the liver, a cyst, the size a of bantam's egg, with thick walls, was opened, containing thread-like materials of a dark-green colour, and on the floor of this cyst was a collection of yellowish-green crystalline bodies. The other organs were healthy.

CASE 2. Loss of voice; urgent laryngeal spasm ; tracheotomy ; relief.-Elizabeth B-, aged twenty-nine years, married, was admitted on December 16th, 1878, with loss of voice, and occasional attacks of suffocative dyspnoea, which at times threatened her life. This patient was a sister to J. C-, whose case is recorded above. She had always enjoyed fairly good health until her last confinement in July, 1877, since which time she had noticed that her voice had become gradually weaker. She had had very little dyspnoea until the last month, when it had been urgent at times. Her general appearance was fairly good, though she thought she had lost flesh a little lately. She was seven months pregnant.

Her general health being good, it was determined to try the effect of mercurials, and half a drachm of the mercurial ointment was ordered to be rubbed into the armpits (alternately) night and morning; a combination of iodide of potassium and solution of perchloride of mercury was given internally; and the patient was also ordered to inhale nitrate of silver, as in the preceding case. She was confined to a small ward by herself, and the air was kept moistened by steam.

On Dec. 19th she had a somewhat urgent attack of dyspnoea in the morning. A consultation was held as to the advisability of performing tracheotomy, but it was decided to give the treatment already adopted a further trial of some days. 'Two grains of calomel and half a grain of opium were 